\title{
Case Report \\ Detection of Chromosome X;18 Breakpoints and Translocation of the Xq22.3;18q23 Regions Resulting in Variable Fertility Phenotypes
}

\author{
Attila Szvetko, ${ }^{1}$ Nicole Martin, ${ }^{2}$ Chris Joy, ${ }^{3}$ Andrea Hayward, ${ }^{1}$ Bob Watson, ${ }^{4}$ Andrew Cary, ${ }^{5}$ \\ and Stephen Withers ${ }^{1}$ \\ ${ }^{1}$ Genetics Department, Genesis Clinical Genetics, Suite 3 Allamanda Medical Centre, 25 Spendelove Street, \\ Southport, Qld 4215, Australia \\ ${ }^{2}$ Cytogenetics Laboratory, Queensland Fertility Group, 1st Floor, 225 Wickham Terrace, Brisbane, Qld 4000, Australia \\ ${ }^{3}$ Genetics Department, QML Pathology, 11 Riverview Place, Metroplex on Gateway, Murarrie, Qld 4172, Australia \\ ${ }^{4}$ Brisbane IVF Clinic, Queensland Fertility Group, 125 Flockton Street, Everton Park, Brisbane, Qld 4053, Australia \\ ${ }^{5}$ Gold Coast IVF Unit, Fertility Gold Coast, Pindara Private Hospital, 13 Carrara Street, Benowa, QLD 4217, Australia
}

Correspondence should be addressed to Attila Szvetko, a.szvetko@griffith.edu.au

Received 13 October 2011; Accepted 3 November 2011

Academic Editors: D. J. Bunyan and C. López Ginés

Copyright ( $\odot 2012$ Attila Szvetko et al. This is an open access article distributed under the Creative Commons Attribution License, which permits unrestricted use, distribution, and reproduction in any medium, provided the original work is properly cited.

\begin{abstract}
We describe a familial pattern of gonosomal-autosomal translocation between the $\mathrm{X}$ and 18 chromosomes, balanced and unbalanced forms, in male and female siblings. The proposita was consulted for hypergonadotropic hypogonadism. Karyotype analysis revealed a balanced $46, \mathrm{X}, \mathrm{t}(\mathrm{X} ; 18)(\mathrm{q} 22.3 ; \mathrm{q} 23)$ genotype. The sister of the proband presented with oligomenorrhea with irregular menses and possesses an unbalanced form of the translocation 46, $\mathrm{X}, \operatorname{der}(\mathrm{X}), \mathrm{t}(\mathrm{X} ; 18)(\mathrm{q} 22.3$; $\mathrm{q} 23)$. The brother of the proband was investigated and was found to possess the balanced form of the same translocation, resulting in disrupted spermatogenesis. Maternal investigation revealed the progenitor karyotype 46, X, t(X;18)(q22.3;q23). Maternal inheritance and various genomic events contributed to the resultant genotypes. Primary infertility was initially diagnosed in all progeny; however, the male individual recently fathered twins. We briefly review the mechanisms associated with X;18 translocations and describe a pattern of inheritance, where breakpoints and translocation of the Xq22.3;18q23 regions have resulted in variable fertility.
\end{abstract}

\section{Introduction}

Numerous X-chromosomal translocations have been reported in the literature. The phenotypic manifestations of these translocations depend on several factors including the nature of the translocation: $\mathrm{X}$-autosomal, Y-autosomal, or X$\mathrm{Y}$ chromosomal exchange, as well as the pattern of inheritance, segregation, and gene inactivation [1,2]. Most fertility mutations affect gonad function, but it is also apparent that a number of fertility genes are yet to be realised [3]. Historically, autoradiographical analyses delineated common patterns of X-chromosomal replication and inactivation of reciprocal autosomes $[4,5]$. X-autosome translocations can effect fertility where chromosomal changes result in inactivation of genes governing reproduction [6]. Gonosomalautosomal translocations are distinct aberrations, which involve an autosome and/or gonosome (sex chromosome). These variations involve site-specific loss or gain of genetic material with the latter type giving rise to trisomies, the former being monosomies. Translocations of this class can be complex [7]. Studies examining X-chromosome deletions have predicted that Xq aberrations within the Xq13-Xq27 region can result in premature gonad failure [8]. X-autosome translocation causing gonadal dysgenesis with bilateral streak gonads as well as aberrant ovarian and sex development has been demonstrated by numerous studies $[9,10]$. Translocations involving the long arms of the X-chromosome and several autosomes $(X ; 1-4,6-9,11,12,14,15,17,19,21$, and 22), resulting in various degrees of gonad dysfunction, have also been reported [8]. Recently, it has become evident that breakpoints in the critical region on Xq21 play a significant role in premature ovarian failure (POF) due 


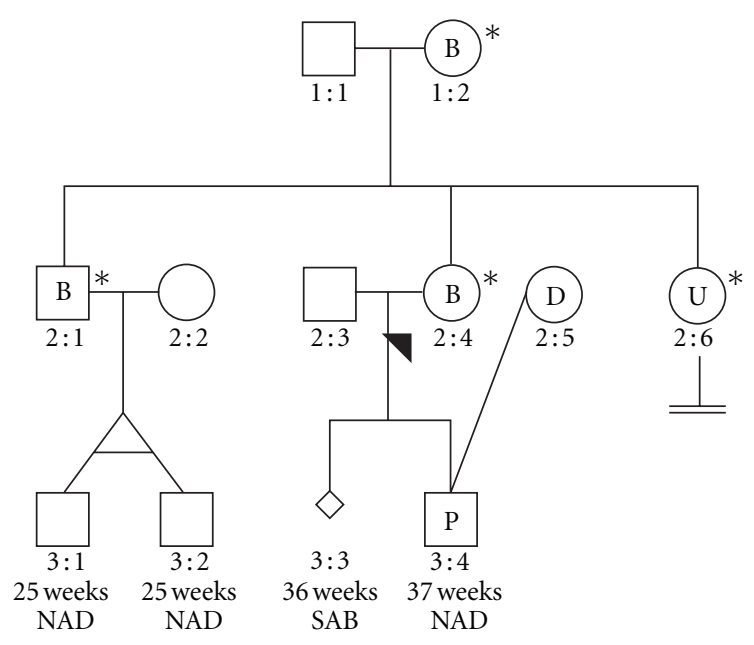

Figure 1: Pedigree. ${ }^{*}$ Affected individual detected. B: balanced translocation detected; 46, X, t(X;18)(q22.3;q23). U: Unbalanced translocation detected; 46, $\mathrm{X}, \operatorname{der}(\mathrm{X}), \mathrm{t}(\mathrm{X} ; 18)(\mathrm{q} 22.3 ; \mathrm{q} 23) . \mathrm{D}$ : donor-individual $2: 4$ carried pregnancy $3: 4$ using donor egg (from individual 2:5) and partner's sperm (from individual 2:3). P: Pregnancy resulted from donor egg (from individual 2:5). SAB: spontaneous abortion (individual 3:3). NAD: no abnormalities detected.

to effects on flanking genes [11]. Reciprocal translocations between autosomes and gonosomes are irregularities that appear to contribute significantly to primary infertility. In the current paper, we describe a case of X;18 translocation in an Australian kindred, resulting in various degrees of infertility in both male and female siblings.

\section{Case Presentation}

The proposita is the second of three siblings (Figure 1; individual 2:4), conceived when the mother was 21 years of age. Individual 2:4 was first consulted at 33 years of age upon referral for suspected infertility. Initial investigations revealed hypergonadotropic hypogonadism (elevated gonadotrophins with low estradiol and progesterone), indicating poor ovarian function with ovarian resistance. Results were confirmed on several occasions, and premature menopause was diagnosed. Following a short course of ovulatory induction, this patient experienced an early pregnancy at age 36; however, that pregnancy resulted in spontaneous abortion at 36-week gestation (individual $3: 3)$. Sporadic chromosomal abnormalities as well as both maternal and paternal meiotic errors may contribute to unsuccessful pregnancies of this type [12]. Recently, individual $2: 4$ successfully conceived a male child (Individual $3: 4$ ) following assisted fertility therapy using donor ovum (from Individual 2:5) and partner sperm (from individual 2:3). That pregnancy lasted 37 weeks, and the progeny (individual $3: 4)$ was born without complication. The patient had been previously investigated for suitability to in vitro fertilization, which had on that occasion confirmed ovarian resistance. Both the proband and her partner underwent chromosome analysis. Individual $2: 3$ was determined karyotypically normal (46XY). For individual 2:4, cytogenetic studies revealed a 46XX genotype with balanced translocation of the long arms of an $\mathrm{X}$-chromosome and the distal region of chromosome 18 (46, X, $\mathrm{t}(\mathrm{X} ; 18)(\mathrm{q} 22.3 ; \mathrm{q} 23)$. The couple was informed of potentially viable pregnancy outcomes, and it was explained that the translocation was the most likely cause of the apparent ovarian failure, owing to a relative X-monosomy with partial inactivation of the second $\mathrm{X}$-chromosome. The likelihood of the production of a chromosome 18 trisomy, leading to Edwards syndrome was discussed. Consultation regarding assisted reproductive technologies and preimplantation genetic diagnosis were undertaken. Analysis of chromosomal segregation patterns showed that of the 16 possible segregations (meiotic), only 2 could yield normal or balanced gametes. The risk of producing potential carrier siblings was discussed (Table 1).

The proband's brother, the first of three siblings (individual $2: 1$ ), was conceived at 19 years maternal age. He was aged 36 years at the time of initial presentation and was referred for fertility testing. On examination, the patient was phenotypically normal. Genomic analysis revealed a balanced $\mathrm{X} ; 18$ translocation (46, Y, $\mathrm{t}(\mathrm{X} ; 18)(\mathrm{q} 22.3 ; \mathrm{q} 23))$. Concerns regarding the likelihood of infertility were discussed. Xautosome translocations are known to interfere with meiosis leading to disrupted spermatogenesis. It is known that most males and approximately half of all females with $\mathrm{X}$-autosome translocations experience sterility [3]. Balanced reciprocal translocations are amongst the most common chromosomal abnormalities. Rearrangements usually result in sterility and/or a higher risk of chromosomal imbalance among offspring [13]. Seminal fluid analysis was conducted and individual 2:1 was found to have decreased motile sperm count $(<25 \%)$, increased sluggish/nonprogressive sperm $(90 \%)$, as well as elevated abnormal spermatozoa (99\%). Overall, analysis showed quantitatively normal seminal fluid with reduced motility, with the increased presence of abnormal forms. The limited prospects of successful conception were discussed with the couple (individuals $2: 1$ and $2: 2$ ).

The sister of the proband is the youngest of the three siblings (individual 2:6) and was conceived at 25 years maternal age. She was referred with oligomenorrhea and irregular menstrual cycles (ranging from nil for 6 months to 5-week-long cycles). Cytogenetic analysis revealed a 46, $\mathrm{X}, \operatorname{der}(\mathrm{X}), \mathrm{t}(\mathrm{X} ; 18)(\mathrm{q} 22.3 ; \mathrm{q} 23)$ unbalanced translocation, that is, trisomic $18 \mathrm{q}$ karyotype. Other than the genotype, the subject was and continues to be phenotypically normal. She was further counselled regarding the decreased likelihood of successful pregnancy, and the translocation implications were explained.

The mother of the proband was consulted (individual $1: 2$ ). She had previously experienced three uncomplicated pregnancies at the ages of 19,21 , and 25 years. Chromosomal analysis revealed 46, $\mathrm{X}, \mathrm{t}(\mathrm{X} ; 18)(\mathrm{q} 22.3 ; \mathrm{q} 23)$ with a balanced reciprocal translocation between the long arms of one Xchromosome and chromosome 18 (18q). Cytogenetic analysis showed breakpoints at Xq22.3 and 18q23. This patient is phenotypically normal. Although Xq22 breakpoints may be associated with ovarian dysfunction, the patient reported no fertility issues and had previously produced three offspring, 
TABLE 1: Theoretical meiotic segregation patterns for translocation: 46, $\mathrm{X}, \mathrm{t}(\mathrm{X} ; 18)(\mathrm{q} 22.3 ; \mathrm{q} 23)$.

\begin{tabular}{lcc}
\hline Segregation type & Cell 1 & Cell 2 \\
\hline Alternate (result is balanced or normal) $^{\mathrm{a}}$ & $\mathrm{X}+18$ & $\operatorname{der}(\mathrm{X})+\operatorname{der}(18)$ \\
Adjacent $^{\mathrm{b}}$ & $\mathrm{X}+\operatorname{der}(18)$ & $\mathrm{der}(\mathrm{X})+18$ \\
Adjacent $^{\mathrm{b}}$ & $\mathrm{X}+\operatorname{der}(\mathrm{X})$ & $18+\operatorname{der}(18)$ \\
Tertiary trisomy $^{\mathrm{b}}$ & $\mathrm{X}+18+\operatorname{der}(\mathrm{X})$ & $\mathrm{der}(18)$ \\
Tertiary trisomy $^{\mathrm{b}}$ & $\mathrm{X}+18+\operatorname{der}(18)$ & $\mathrm{der}(\mathrm{X})$ \\
Interchange trisomy $^{\mathrm{b}}$ & $\operatorname{der}(\mathrm{X})+\operatorname{der}(18)+\mathrm{X}$ & 18 \\
Interchange trisomy $^{\mathrm{b}}$ & $\operatorname{der}(\mathrm{X})+\operatorname{der}(18)+18$ & $\mathrm{X}$ \\
$4: 0^{\mathrm{b}}$ & $\mathrm{X}+\operatorname{der}(\mathrm{X})+18+\operatorname{der}(18)$ & - \\
\hline
\end{tabular}

${ }^{a}$ Normal or balanced meiotic segregation pattern.

${ }^{b}$ Abnormal theoretical meiotic segregation pattern.

which resulted from uncomplicated full-term pregnancies. Pregnancies in such situations run the risk of unknowingly producing unbalanced gametes owing to their clinically silent presentation, which indeed was the case in this instance.

\section{Discussion}

In the current pedigree, we investigated three siblings conceived at maternal ages 19,21, and 25 years, for chromosomal translocations, which were inherited from their mother who possesses a 46, X, t(X;18)(q22.3;q23) genotype. She carries a balanced form of the $\mathrm{X} ; 18$ translocation, whilst two of the siblings carry the balanced form and one the unbalanced form. Pedigree analysis showed that the mother imparted the affected X-chromosome with the son carrying the altered complement. The proposita initially presented with a history of miscarriage and signs of ovarian deficiency. Genomic investigations determined the proband genotype to be a balanced 46, X, $t(X ; 18)(q 22.3 ; \mathrm{q} 23)$. The younger female sibling of the proband (Individual 2:6) was consulted, and although phenotypically normal, was found to possess an unbalanced translocation: 46, X, $\operatorname{der}(\mathrm{X}), \mathrm{t}(\mathrm{X} ; 18)(\mathrm{q} 22.3 ; \mathrm{q} 23)$. The primary concern was reduced likelihood of successful conception. The eldest male sibling (individual 2:1) was tested and found to possess a balanced form of the X; 18 translocation (46, Y, $\mathrm{t}(\mathrm{X} ; 18)(\mathrm{q} 22.3 ; \mathrm{q} 23))$. This individual went on to recently father monozygotic twins (individuals $3: 1$ and $3: 2$ ). The twins were born at 25 weeks but show no obvious effects from the prematurity, or otherwise.

Autosomal translocations are relatively common; gonosome-autosome translocations with rearrangement of genes are rather unique. In the current case, a mix of both balanced and unbalanced translocation between the X- and 18 chromosomes has led to various degrees of fertility. Several interesting points punctuate the case; the mother's normal phenotype, the balanced/unbalanced inheritance pattern in the daughters, and the absence of clinically recognizable dysfunction other than described for the male sibling. The typical clinical characteristics of the unbalanced translocation (dysmorphic features, organ malformation, and retardation) are not present, and successful progeny for the male individual (individual 2:1) serves to distinguish the case. It is known that most males with this type of anomaly are completely spermtogenically impaired; however, this is not the case with the investigated male. Previous research has postulated that regions on the Y-chromosome as well as various autosomes may contribute to successful spermatogenesis in the presence of X-chromsomal aberrations [14]. Ychromosomal compensation may be an explanation for the successful conception of the twins in this case.

In females, the phenotype depends on the position of the breakpoint as well as the functional status of the remaining X-chromosome. Approximately $75 \%$ of patients will have one active/one inactive X, while approximately $25 \%$ will have inactivation of the X-chromosome in only some cells. Females with an active $\mathrm{X}$ in all cells with the breakpoint not within any functional gene show a higher incidence (approximately 50\%) of ovarian failure (mainly breakpoints within the Xq13-q26 critical region) [3]. In this case, the female siblings carry the balanced (individual 2:4) and unbalanced (individual $2: 6$ ) X;18 translocation with breakpoints at q22.3-q23. These changes have caused ovarian dysfunction. X-chromosomal activation/inactivation combined with variable gene expression can occur because translocated genetic material from the X-chromosome may or may not be reactivated once translocated [15]. Ovarian failure can result from X-chromosomal abnormalities, autosomal recessive genes causing various types of XX gonadal dysgenesis, and autosomal dominant gene expression. The exact Xchromosomal loci responsible can be difficult to localize, but there is evidence to suggest that in aggregate, these genes regulate ovarian maintenance. $\mathrm{X}$-monosomies are known to result in accelerated germ-cell atresia [16]. The two known fertility genes mapped to the region Xq22.3-23 are the testis expressed 13A and 13B genes (TEX13A and TEX13B, resp.), and little is known about their functions. It is believed that TEX13A and TEX13B are involved in testicular development (spermatogonially expressed, germcell-specific genes) and it has been noted that they are well conserved across chimpanzee, dog, cow, mouse as well as Homo sapiens [1]. Although only limited information exists regarding this region, the $\mathrm{X}$-chromosome has a predominant role in premeiotic stages of mammalian spermatogenesis, and an abundance of $\mathrm{X}$-linked genes is known to be expressed in spermatogonia [17]. The only known ovarian-resistance/ maintenance related gene within the area of interest Xq13-26 
is the Drosophila melanogaster homologue DIAPH2 (DIA). Aberrations in DIAPH2 are known to result in sterility in both male and female Drosophila, but its function in humans is not well defined [18]. DIAPH2 regulates cytokinesis, which has a direct influence on oogenesis and follicle maturation. Two of the most prominent ovarian dysfunction genes with human homologues at the $\mathrm{X}$ and 18 chromosomes are the B-cell/lymphoma 2; $\mathrm{Bcl}$-2 (human homologue 18q21.3) and zinc finger protein, X-linked; $Z f x$ (human homologue $\mathrm{Xp} 21.3$ ) genes. $\mathrm{Bcl}-2$ has been shown in knockout models to be involved in the accelerated atresia of primordial follicles, whilst deletion of $Z f x$ results in reduced number of oocytes and general infertility by way of reduced germ cells [19, 20]. The ZFX gene in humans also shares characteristics with the zinc finger protein 711 gene (ZNF711), located Xq21.1-q21.2, which codes for a protein which acts as a transcription activator, presumably for fertility-related-gene regulatory elements [21]. In the current case, breakpoints and translocation of the Xq22.3;18q23 region are responsible for the characteristic pattern of presentation. Investigation and ongoing analysis of such anomalies may explain the often idiopathic nature of primary infertility syndromes.

\section{Conflict of Interests}

The authors declare that they have no conflict of interests.

\section{Acknowledgments}

The authors wish to thank the patients and their families for their participation in this study. They also wish to thank the participating clinicians, laboratory, and clinic staff for their assistance, and thank the coauthors for their help with preparation of the paper.

\section{References}

[1] S. Lee, S. H. Lee, T. G. Chung et al., "Molecular and cytogenetic characterization of two azoospermic patients with X-autosome translocation," Journal of Assisted Reproduction and Genetics, vol. 20, no. 9, pp. 385-389, 2003.

[2] M. J. Pinho, R. Neves, P. Costa et al., "Unique t(Y;1)(q12;q12) reciprocal translocation with loss of the heterochromatic region of chromosome 1 in a male with azoospermia due to meiotic arrest: a case report," Human Reproduction, vol. 20, no. 3, pp. 689-696, 2005.

[3] L. C. Layman, "Human gene mutations causing infertility," Journal of Medical Genetics, vol. 39, no. 3, pp. 153-161, 2002.

[4] M. M. Cohen, C. C. Lin, V. Sybert, and E. J. Orecchio, "Two human $\mathrm{X}$-autosome translocations identified by autoradiography and fluorescence," The American Journal of Human Genetics, vol. 24, no. 5, pp. 583-597, 1972.

[5] M. Lucas and A. Smithies, "Banding patterns and autoradiographic studies of cells with an X autosome translocation," Annals of Human Genetics, vol. 37, no. 1, pp. 9-12, 1973.

[6] J. T. Leisti, M. M. Kaback, and D. L. Rimoin, "Human X autosome translocations: differential inactivation of the $\mathrm{X}$ chromosome in a kindred with an X-9 translocation," The American Journal of Human Genetics, vol. 27, no. 4, pp. 441453, 1975.
[7] K. Stouffs, H. Tournaye, I. Liebaers, and W. Lissens, "Male infertility and the involvement of the X chromosome," Human Reproduction Update, vol. 15, no. 6, pp. 623-637, 2009.

[8] K. Madan, P. G. A. Hompes, J. Schoemaker, and C. E. Ford, "Xautosome translocation with a breakpoint in Xq22 in a fertile woman and her 47,XXX infertile daughter," Human Genetics, vol. 59, no. 4, pp. 290-296, 1981.

[9] T. Mohandas, R. L. Geller, and P. H. Yen, "Cytogenetic and molecular studies on a recombinant human X chromosome: implications for the spreading of X chromosome inactivation," Proceedings of the National Academy of Sciences of the United States of America, vol. 84, no. 14, pp. 4954-4958, 1987.

[10] N. J. Carpenter, B. Say, and D. Browning, "Gonadal dysgenesis in a patient with an X;3 translocation: case report and review," Journal of Medical Genetics, vol. 17, no. 3, pp. 216-221, 1980.

[11] F. Rizzolio, S. Bione, C. Sala et al., "Chromosomal rearrangements in $\mathrm{Xq}$ and premature ovarian failure: mapping of 25 new cases and review of the literature," Human Reproduction, vol. 21, no. 6, pp. 1477-1483, 2006.

[12] W. P. Robinson, D. E. McFadden, and M. D. Stephenson, "The origin of abnormalities in recurrent aneuploidy/polyploidy," The American Journal of Human Genetics, vol. 69, no. 6, pp. 1245-1254, 2001.

[13] A. Perrin, N. Douet-Guilbert, M. J. Le Bris et al., "Segregation of chromosomes in sperm of a $\mathrm{t}(\mathrm{X} ; 18)(\mathrm{q} 11 ; \mathrm{p} 11.1)$ carrier inherited from his mother: case report," Human Reproduction, vol. 23, no. 1, pp. 227-230, 2008.

[14] A. C. Chandley, "Genetic contribution to male infertility," Human Reproduction, vol. 13, supplement 3, pp. 76-788, 1998.

[15] M. F. Lyon, "X-chromosome inactivation spreads itself: effects in autosomes," The American Journal of Human Genetics, vol. 63, no. 1, pp. 17-19, 1998.

[16] J. L. Simpson and A. Rajkovic, "Ovarian differentiation and gonadal failure," The American Journal of Medical Genetics, vol. 89, no. 4, pp. 186-200, 1999.

[17] P. J. Wang, J. R. McCarrey, F. Yang, and D. C. Page, "An abundance of X-linked genes expressed in spermatogonia," Nature Genetics, vol. 27, no. 4, pp. 422-426, 2001.

[18] D. H. Castrillon and S. A. Wasserman, "Diaphanous is required for cytokinesis in Drosophila and shares domains of similarity with the products of the limb deformity gene," Development, vol. 120, no. 12, pp. 3367-3377, 1994.

[19] Y. Morita, G. I. Perez, D. V. Maravei, K. I. Tilly, and J. L. Tilly, "Targeted expression of Bcl-2 in mouse oocytes inhibits ovarian follicle atresia and prevents spontaneous and chemotherapy-induced oocyte apoptosis in vitro," Molecular Endocrinology, vol. 13, no. 6, pp. 841-850, 1999.

[20] S. W. Luoh, P. A. Bain, R. D. Polakiewicz et al., "Zfx mutation results in small animal size and reduced germ cell number in male and female mice," Development, vol. 124, no. 11, pp. 2275-2284, 1997.

[21] S. L. Lloyd, C. A. Sargent, J. Chalmers, E. Lim, S. S. M. Habeebu, and N. A. Affara, "An X-linked zinc finger gene mapping to Xq21.1-q21.3 closely related to ZFX and ZFY: possible origins from a common ancestral gene," Nucleic Acids Research, vol. 19, no. 18, pp. 4835-4841, 1991. 


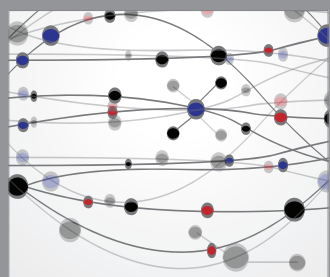

The Scientific World Journal
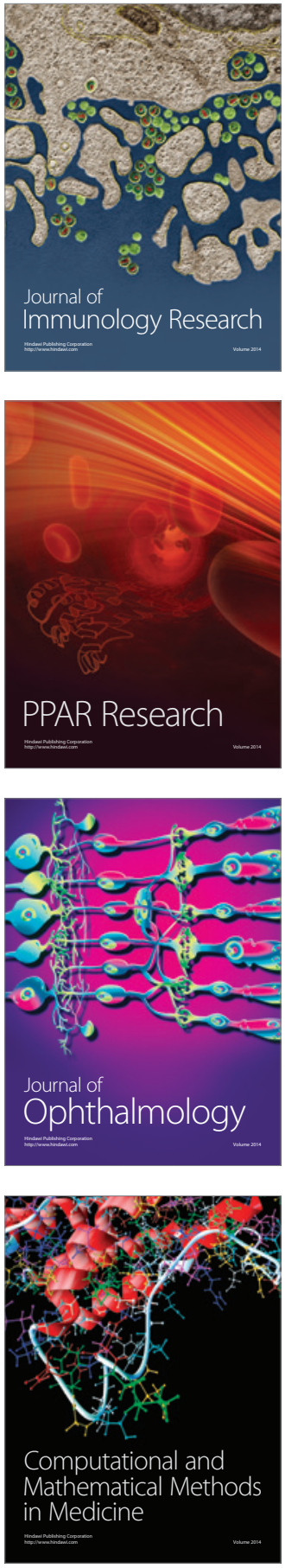

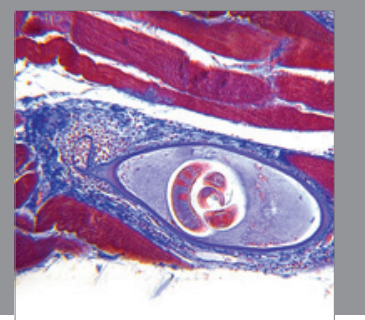

Gastroenterology

Research and Practice
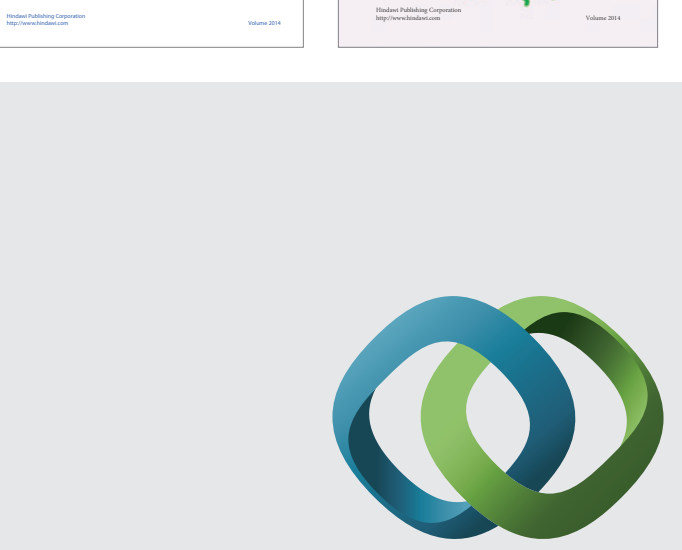

\section{Hindawi}

Submit your manuscripts at

http://www.hindawi.com
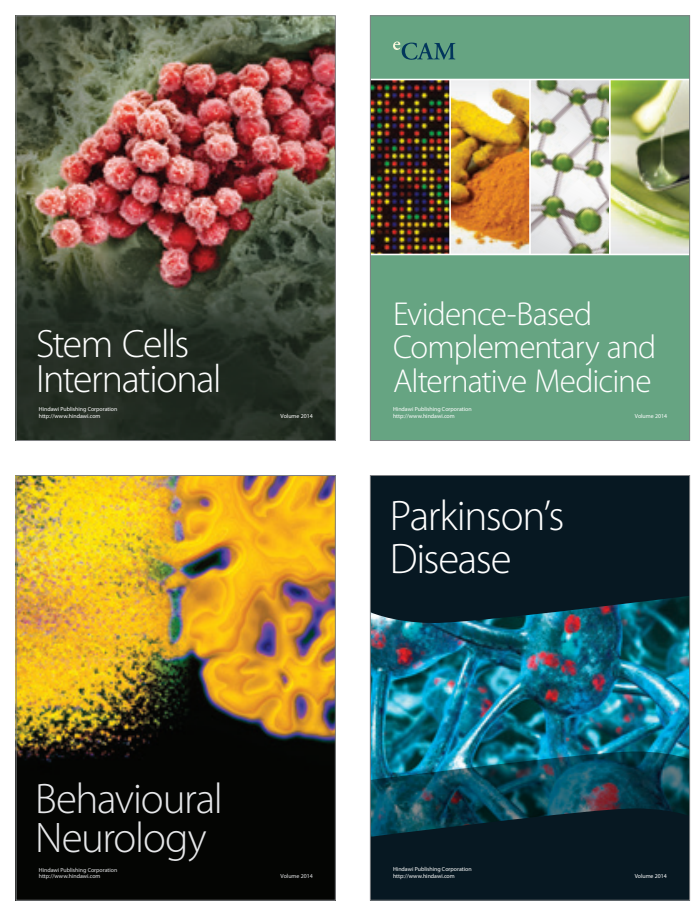

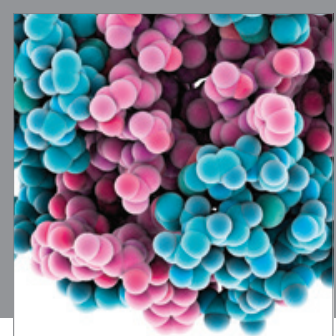

Journal of
Diabetes Research

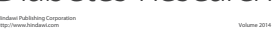

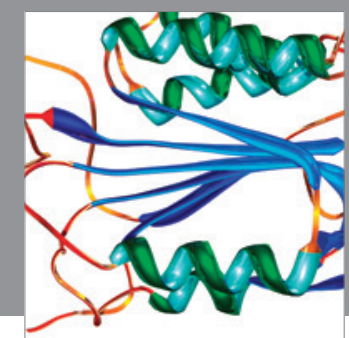

Disease Markers
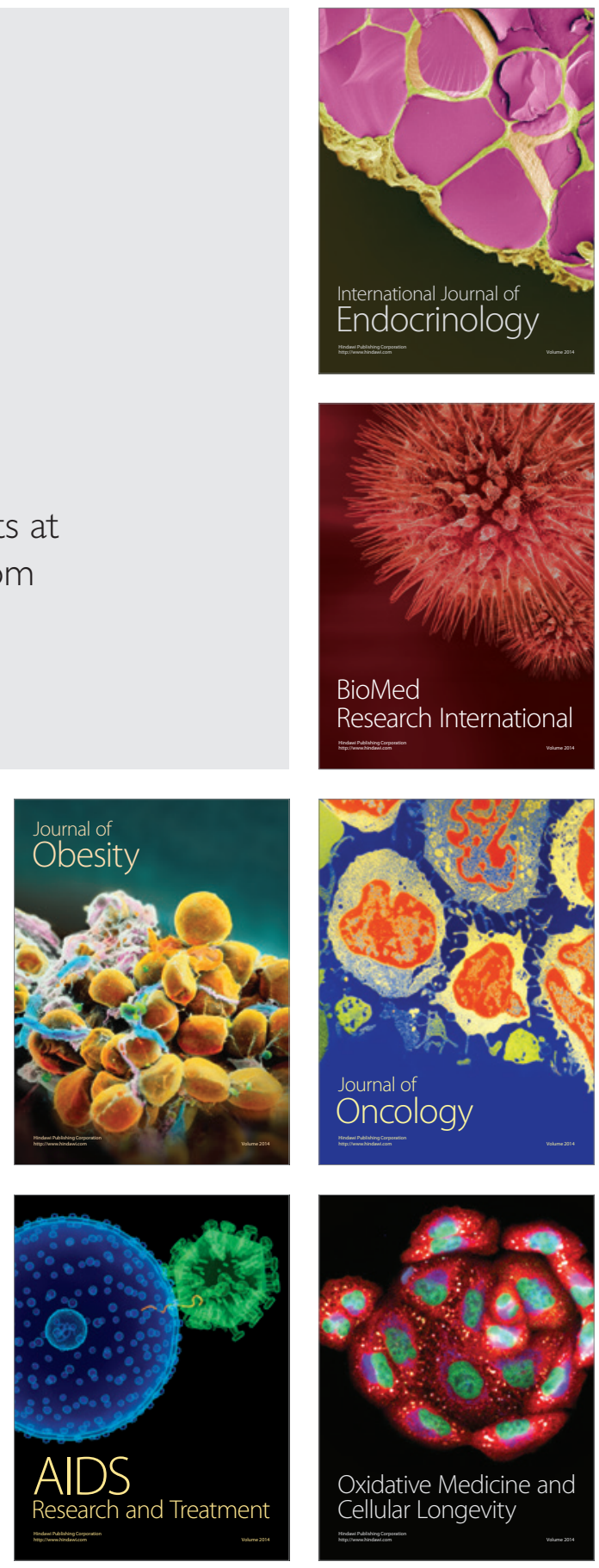